\title{
mPW1PW91 Calculated Structures and IR Spectra of the Conformational Stereoisomers of C-Cyanophenyl Pyrogallol[4]arene
}

\author{
Sangdoo Ahn, 'Tae Jung Park, and Jong-In Choe* \\ Department of Chemistry, Chung-Ang University, Seoul 156-756, Korea \\ *E-mail: sangdoo@cau.ac.kr(S.Ahn); choeji@cau.ac.kr (J.-I. Choe) \\ Received December 11, 2013, Accepted January 6, 2014
}

\begin{abstract}
Molecular structures of the various conformational stereoisomers of 2,8,14,20-cyanophenyl pyrogallol[4]arenes 1 were optimized using the mPW1PW91 (hybrid Hartree-Fock density functional) calculation method. The total electronic and Gibbs free energies and the normal vibrational frequencies of the different structures from three major conformations (CHAIR, TABLE, and 1,2-Alternate) of the four stereoisomers [1(rccc), $\mathbf{1}(r c c t)$, $\mathbf{1}(r c t t)$, and $\mathbf{1}(r t c t)]$ were analyzed. The mPW1PW91/6-31G(d,p) calculations suggested that $\mathbf{1}(r c c t)_{1,2-\mathrm{A}}$, $\mathbf{1}(r c t t)_{\mathrm{CHAIR}}$, and $\mathbf{1}(r t c t)_{\mathrm{CHAIR}}$ were the more stable conformations of the respective stereoisomers. Hydrogen bonding is the primary factor for the relative stabilities of the various conformational isomers, and maximizing the $\pi-\pi$ interaction between the cyanophenyl rings is the secondary factor. The calculated IR spectra of the more stable conformers $\left[\mathbf{1}(r c t t)_{\mathrm{CHAIR}}, \mathbf{1}(r c c t)_{1,2-\mathrm{A}}, \mathbf{1}(r t c t)_{\mathrm{CHAIR}}\right]$ were compared with the experimental IR spectrum of $\mathbf{1}(r c t t)_{\text {CHAIR }}$.
\end{abstract}

Key Words : mPW1PW91, Conformer, Stereoisomer, IR spectrum, Cyanophenyl pyrogallol[4]arene

\section{Introduction}

Calixarenes, which are a class of synthetic macrocycles, have been extensively explored..$^{1-5}$ Resorcinarenes $^{6}$ and pyrogallolarenes ${ }^{7}$ are structurally analogous to calixarenes. Till date, many variants and hybrids of calixarenes, including calixcrowns, ${ }^{8}$ calix[4]resorcinarenes, ${ }^{9}$ and cavitands, ${ }^{10-12}$ have been synthesized.

Molecular capsules, self-assembled from calix[4]arenes, resorcin[4]arenes, cavitands, and pyrogallol[4]arenes, have received increasing interest in recent years. ${ }^{13-24}$ In particular, pyrogallol[4]arenes have drawn much attention since their emergence as new hydrogen-bonded dimeric and hexameric molecular receptors. ${ }^{24-28}$ Many of the dimers are comprised of monomers seamed together, either directly or via hydrogen bond donor/acceptor solvent molecules. ${ }^{29-33}$ The hexameric pyrogallol[4]arene spheroidal structures are held together by hydrogen bonding between the monomers. ${ }^{36-38}$ Pyrogallol[4]arenes have been shown to self-assemble into remarkable multicomponent assemblies, including nanocapsules, nanotubes, and bilayer networks. ${ }^{37}$ The formation of large self-assembled nanocapsules by hydrogen bonding of the upper-rim hydroxyls prompted researchers to attempt encapsulation of target molecules and thus obtain a variety of interesting cocrystals. ${ }^{38-41}$ The synthesis, crystal structure, and IR spectroscopic investigation of C-cyanophenyl pyrogallol[4]arene 1 without any modification of the hydroxyl groups of pyrogallols have been reported. ${ }^{42}$ In this study, we have optimized the conformers (CHAIR, TABLE, 1,2-Alternate) of the four stereoisomers [1(rccc), $\mathbf{1}(r c c t), \mathbf{1}(r c t t)$, and $\mathbf{1}(r t c t)$ ] of 1 using $m$ PW1PW91 (hybrid HF-DF) calculation methods. The primary objective of this research was to determine the structures and relative stability of the different
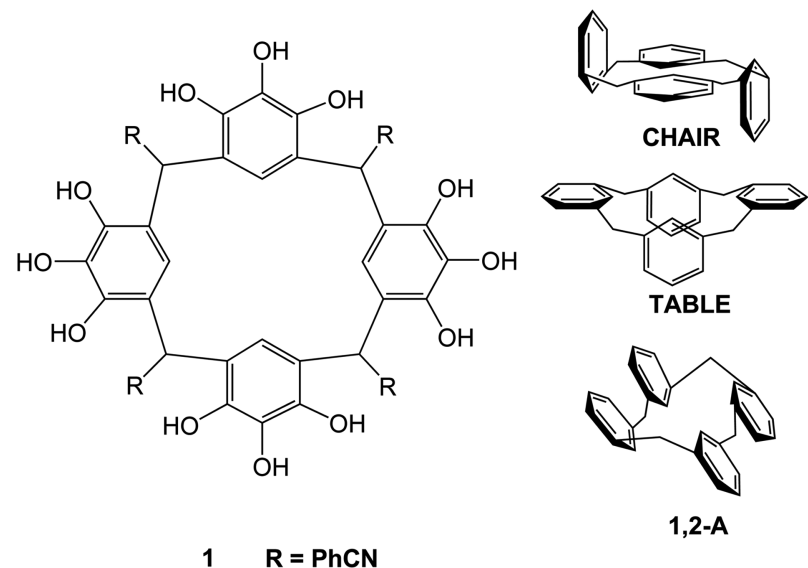

Scheme 1. Chemical structure of 2,8,14,20-cyanophenylpyrogallol[4]arene $\mathbf{1}$ with three stable conformations (TABLE, CHAIR, and 1,2-A) of the calix[4]arene backbone of $\mathbf{1}$.

conformational stereoisomers for $\mathbf{1}$ using the $m$ PW1PW91/ $6-311+G(d, p)$ calculation method. The secondary objective was to compare the calculated IR spectra of the more stable conformers of the four stereoisomers of $\mathbf{1}$ obtained from the $m$ PW1PW91method. These findings might be useful for the design of receptors based on pyrogallol[4]arenes, and in turn, for the construction of superstructures derived from hydrogen bonds or metal coordination.

\section{Computational Methods}

Three major conformations (CHAIR, TABLE, and 1,2Alternate) of the four stereoisomers [1 $(r c c c), \mathbf{1}(r c c t), \mathbf{1}(r c t t)$, $\mathbf{1}(r t c t)$ ] were constructed using the molecular mechanics (MM), molecular dynamics (MD), and semi-empirical cal- 
culations of HyperChem. ${ }^{43}$ Optimized structures were found by conformational searches using a previously described, simulated annealing method. ${ }^{44}$ The stereoisomers of $\mathbf{1}$ obtained from the MM/MD and AM1 calculations were fully reoptimized using the mPW1PW91/6-31G(d) (hybrid HF-DF) calculation method to determine both the relative energies and structures of distinct conformational stereoisomers. Modified Perdew-Wang 1-parameter ( $m$ PW1) calculation methods $^{45,46}$ such as $m$ PW1PW91 are new hybrid HartreeFock density functional (HF-DF) models that help in obtaining remarkable results for both covalent and non-covalent interactions. ${ }^{47}$ Additional mPW1PW91/6-311+G(d,p) optimizations were performed using Gaussian $09^{48}$ to obtain more accurate total electronic energies and structures for the conformational stereoisomers of $\mathbf{1}$.

The mPW1PW91/6-31G(d) method was also used to calculate the normal mode frequencies of the final structures. None of the vibrational spectra showed negative frequencies, confirming that the optimized structures exist in energy minima. For direct comparison with experimental data, the calculated frequencies were scaled by the recommended scale factor $(0.950) .{ }^{49}$ Furthermore, broadened IR spectra were presented assuming a Lorentzian line width of $10 \mathrm{~cm}^{-1}$.

\section{Results and Discussion}

The dispositions of the cyanobenzenyl groups are denoted as cis $(c)$ or trans $(t)$ relative to the reference cyanobenzenyl group $(r)$ with respect to the mean plane defined by the macrocycle. The notation proceeds around the system in a direction from the reference group, which is chosen to prioritize cis over trans and maximize the number of cis. The structures of the three main conformations (CHAIR, TABLE, and 1,2-Alternate) of the four stereoisomers [1 $(r c c c)$, $\mathbf{1}(r c t t), \mathbf{1}(r c c t)$, and $\mathbf{1}(r t c t)]$ were optimized using the mPW1PW91/6-31G(d) (hybrid HF-DF) calculation method to determine both the relative energies and structures of various distinct conformational stereoisomers.

Table 1 shows the total electronic and Gibbs free energies minimized by the mPW1PW91 method with the 6-31G(d) basis set for the distinct conformational isomers. The calculated Gibbs free energies in Table 1 suggest the following: (1) the 1,2-A conformation is the most stable of the $\mathbf{1}$ (rcct) isomers, (2) the CHAIR conformer is also the most stable of the $\mathbf{1}(r t c t)$ stereoisomers, and (3) the CHAIR conformer is the most stable of the $\mathbf{1}(r c t t)$ stereoisomers, which agrees with the conformation $\left(\mathbf{1}(r c t t)_{\mathrm{CHAIR}}\right)$ of the experimental crystal structure. $^{42}$

The electronic energies of these structures were also optimized with the $6-311+\mathrm{G}(\mathrm{d}, \mathrm{p})$ basis set to obtain more accurate total electronic energies and structures for the stereoisomers of 1 . Table 2 reports the additional mPW1PW91 calculated total electronic energies and the dipole moments of the seven conformational stereoisomers of $\mathbf{1}$.

Figure 1 shows three most stable structures $\left(\mathbf{1}(r c c t)_{1,2-\mathrm{A}}\right.$, $\left.\mathbf{1}(r c t t)_{\text {CHAIR, and }} \mathbf{1}(r t c t)_{\text {CHAIR }}\right)$ calculated by the mPW1PW91/ $6-311+G(d, p)$ method. Visualization of the optimized structures in Figure 1 was performed with PosMol. ${ }^{50}$ (Figure S1 in "Supplementary Material" shows the calculated structures of three conformers (CHAIR, TABLE, and 1,2-Alternate) of the respective stereoisomers [1 $(r c c c), \mathbf{1}(r c c t), \mathbf{1}(r c t t)$, and $\mathbf{1}(r t c t)]$ including the less stable conformers.) The frontier orbitals (HOMO and LUMO) for the more stable confor-

Table 2. mPW1PW91/6-311+G(d,p) calculated energies and dipole moments of 1

\begin{tabular}{ccccc}
\hline Disposition & $\begin{array}{c}\text { Confor- } \\
\text { mation }\end{array}$ & $E$ (a. u.) & $\Delta E^{a}$ & $\begin{array}{c}\text { Dipole moment } \\
\text { (Debye) }\end{array}$ \\
\hline \multirow{1}{1}{$($ rccc) $)$} & CHAIR & -3277.3548 & 11.69 & 17.83 \\
& TABLE & -3277.3647 & 5.50 & 11.53 \\
$\mathbf{1}($ rcct $)$ & CHAIR & -3277.3593 & 8.87 & 13.49 \\
& TABLE & -3277.3583 & 9.50 & 10.99 \\
& 1,2-Alternate & -3277.3692 & 2.66 & 16.98 \\
$\mathbf{1}($ rctt $)$ & CHAIR & -3277.3690 & 2.81 & 4.28 \\
& TABLE & -3277.3649 & 5.37 & 8.68 \\
$\mathbf{1}($ rtct $)$ & CHAIR & -3277.3735 & 0.00 & 3.54 \\
& TABLE & -3277.3533 & 12.64 & 8.88
\end{tabular}

${ }^{a}$ The relative energy (in $\mathrm{kcal} / \mathrm{mol}$ ) compared to $\left[\mathbf{1}(r t c t)_{\text {CHAIR }}\right] .{ }^{b}$ Error limits of the dipole moments are 0.01 Debye.

Table 1. mPW1PW91/6-31G(d) calculated total electronic and Gibbs free energies ${ }^{a}$ of $\mathbf{1}$

\begin{tabular}{clcccc}
\hline Disposition $^{b}$ & Conformation & $E$ (a. u.) & $\Delta E^{c}$ & $G$ (a. u.) & $\Delta G^{d}$ \\
\hline \multirow{2}{*}{$\mathbf{1}(r c c c)$} & CHAIR & -3276.4677 & 12.56 & -3275.7538 & 10.54 \\
& TABLE & -3276.4780 & 6.12 & -3275.7636 & 4.38 \\
$\mathbf{1}(r c c t)$ & CHAIR & -3276.4713 & 10.34 & -3275.7589 & 7.35 \\
& TABLE & -3276.4695 & 11.48 & -3275.7566 & 8.74 \\
\multirow{3}{*}{$\mathbf{1}(r c t t)$} & $1,2-$ Alternate & -3276.4877 & 0.00 & -3275.7673 & 2.02 \\
& CHAIR & -3276.4795 & 5.17 & -3275.7684 & 1.36 \\
\multirow{2}{*}{$\mathbf{1}(r t c t)$} & TABLE & -3276.4800 & 4.86 & -3275.7652 & 3.39 \\
& CHAIR & -3276.4850 & 1.69 & -3275.7706 & 0.00 \\
& TABLE & -3276.4672 & 12.89 & -3275.7514 & 12.02 \\
\hline
\end{tabular}

${ }^{a}$ Error limits of total electronic and Gibbs free energies are 0.00001 Hartree (a. u.). ${ }^{b}$ The dispositions of the cyanobenzenyl groups are denoted by $c i s$ (c) or trans $(t)$ relative to the reference cyanobenzenyl group $(r)$ with respect to the mean plane defined by the macrocycle, as suggested by Bohmer. ${ }^{1}$ The notation proceeds around the system in a direction from the reference group, which is chosen in order to prioritize cis over trans and maximize the number of $c i s .{ }^{c}$ The relative energy (in $\left.\mathrm{kcal} / \mathrm{mol}\right)$ compared to $\left[\mathbf{1}(r c c t)_{1,2-\mathrm{A}}\right] .{ }^{d}$ The relative Gibbs free energy (in $\left.\mathrm{kcal} / \mathrm{mol}\right) \mathrm{compared}$ to [1 $\left.(r t c t)_{\mathrm{CHAIR}}\right]$. 


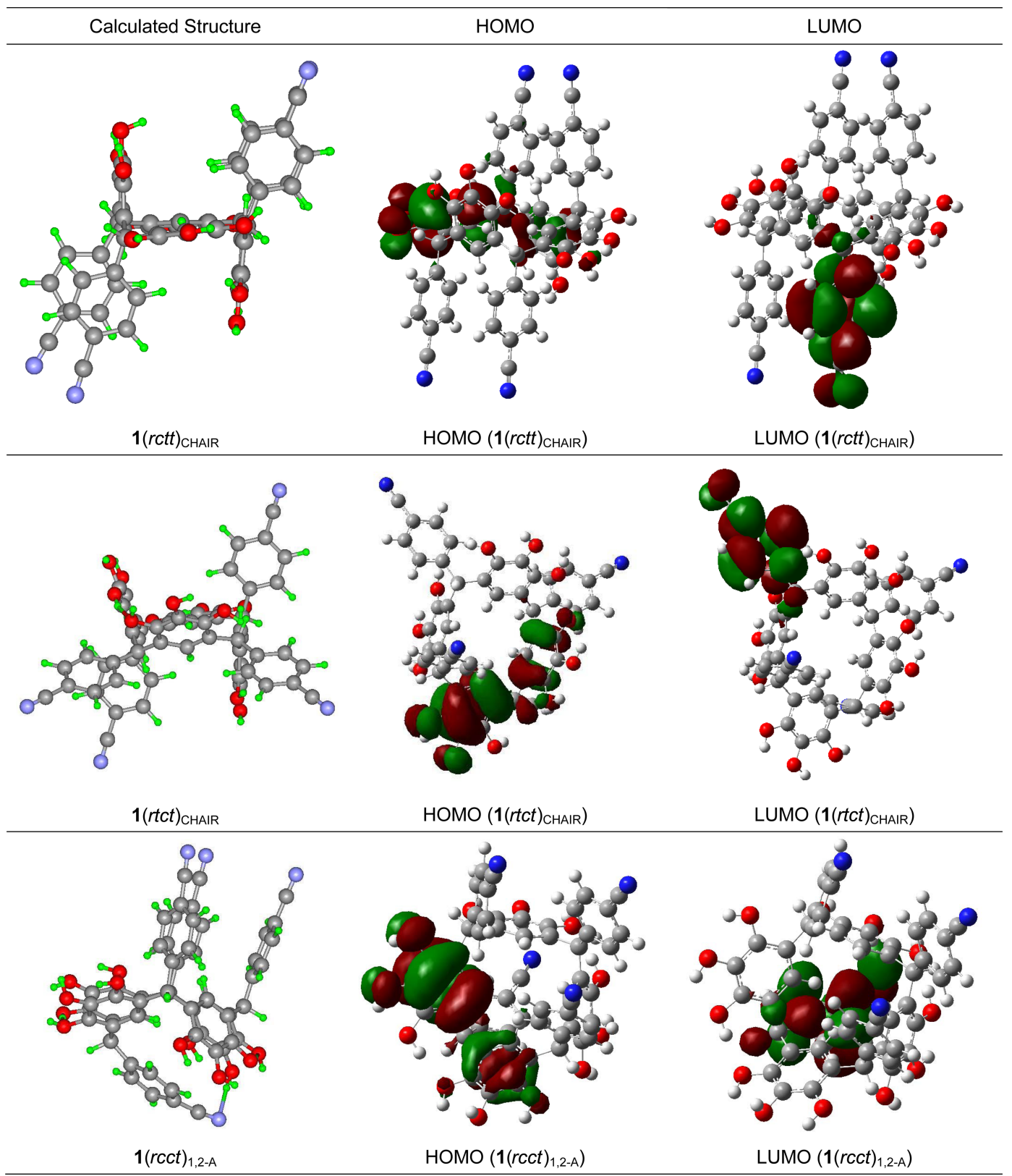

Figure 1. $m \mathrm{PW} 1 \mathrm{PW} 91 / 6-311+\mathrm{G}(\mathrm{d}, \mathrm{p})$ calculated structures of 1. Visualization of the optimized structures was performed with PosMol. ${ }^{50}$ The frontier orbitals (HOMO and LUMO) for the more stable conformations of $\mathbf{1}\left(\mathbf{1}(r c t t)_{\text {CHAIR }}, \mathbf{1}(r t c t)_{\text {CHAIR }}\right.$, and1 $\left.(r c c t)_{1,2-\mathrm{A}}\right)$ are drawn by Gauss View. ${ }^{51}$

mations of $\mathbf{1}\left(\mathbf{1}(r c c t)_{1,2-\mathrm{A}}, \mathbf{1}(r c t t)_{\mathrm{CHAIR}}\right.$, and $\left.\mathbf{1}(r t c t)_{\mathrm{CHAIR}}\right)$ were drawn using GaussView. ${ }^{51}$ The HOMO orbitals of these three conformers are mainly located at the pyrogallolarene moieties. However, the LUMO orbital in each conformer is located at one of the cyanophenyl groups.

It is well established that the substitution of aryls for alkyls on methine units connecting the pyrogallols of pyrogallol[4] arene yields a chair conformation. ${ }^{52,53}$ The CHAIR conformer of $\mathbf{1}(r c t t)$ exhibits $\mathrm{C} 2$ symmetry around the centroid of pyrogallol[4]arene (Fig. 1). Two 4-cyanophenyl substituents pointing along the same direction face each other so that the $\pi-\pi$ interaction between the cyanophenyl rings is maximized. At the terminal of the cyanophenyl rings, the calculated distances between two nitrogen atoms are $4.954 \AA$ and 5.028

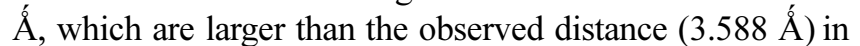
the crystal structure ${ }^{42}$ and the typically required distance $(3.400 \AA)^{54}$ for $\pi-\pi$ interaction in phenyl rings.

The experimental IR spectrum ${ }^{42}$ and $m$ PW1PW91/6$31 \mathrm{G}(\mathrm{d})$ calculated IR spectra (Fig. 2) of the more stable conformers $\left[\mathbf{1}(r c t t)_{\text {CHAIR }}, \mathbf{1}(r t c t)_{\text {CHAIR, }}\right.$ and $\left.\mathbf{1}(r c c t)_{1,2-\mathrm{A}}\right]$ of the respective stereoisomers of $\mathbf{1}$ are compared in Table 3 . The main features (frequencies and intensities) of the conformational stereoisomers differ only slightly in the low-frequency range. However, the high-frequency vibrations of free and restricted $\mathrm{O}-\mathrm{H}$ bond stretching correspond to a wide wavenumber range, between 3300 and $3600 \mathrm{~cm}^{-1}$, depend- 
Table 3. Experimental and calculated vibrational frequencies of the more stable conformational isomers of 1

\begin{tabular}{|c|c|c|c|c|c|c|}
\hline \multicolumn{3}{|c|}{ Experimental $^{42}$} & \multicolumn{4}{|c|}{ Calculated } \\
\hline \multicolumn{2}{|c|}{$\mathbf{1}(r c t t)_{\text {CHAIR }}$} & \multirow{2}{*}{$\begin{array}{c}\text { 1(Stereoisomer) } \\
\text { Vibrational modes }\end{array}$} & \multicolumn{2}{|c|}{$\begin{array}{l}\text { 1(rctt })_{\text {CHAIR }} \\
\text { Fig. 2(a) }\end{array}$} & \multirow{2}{*}{$\begin{array}{c}\mathbf{1}(r t c t)_{\text {CHAIR }} \\
\text { Fig. 2(b) } \\
\text { Energy } / \mathrm{cm}^{-1}\end{array}$} & \multirow{2}{*}{$\begin{array}{c}\text { 1(rcct })_{12 \mathrm{~A}} \\
\text { Fig. } 2(\mathrm{c}) \\
\text { Energy } / \mathrm{cm}^{-1}\end{array}$} \\
\hline Energy $/ \mathrm{cm}^{-1}$ & Intensity & & Energy $/ \mathrm{cm}^{-1}$ & Int. $^{a}$ & & \\
\hline 500 & weak & $\mathrm{O}-\mathrm{H}$ wagging & 390,517 & medium & 390 & 525 \\
\hline 610 & medium & Ring breathing, $\mathrm{C}-\mathrm{H}$ wagging & 560 & weak & 577 & 551,555 \\
\hline 820,875 & medium & $\mathrm{OH}$ wagging $+\mathrm{C}-\mathrm{O}$ stretching & 810 & weak & 773,842 & 805 \\
\hline 1050 & medium & C-O stretching & 1000,1066 & medium & 996,1073 & 974 \\
\hline 1120 & medium & C-O stretching & 1192 & medium & 1201 & 1186 \\
\hline 1220,1280 & medium & C-O stretching & 1280 & strong & 1278,1321 & 1252,1303 \\
\hline 1470,1520 & medium & $\begin{array}{c}\mathrm{C}-\mathrm{O}_{\mathrm{ar}} \text { stretching }+\mathrm{C}-\mathrm{C}_{\mathrm{ar}} \text { stretching } \\
+\mathrm{CCC}_{\mathrm{ar}} \text { bending }\end{array}$ & 1466 & strong & $1466 \sim 1501$ & $1457 \sim 1487$ \\
\hline 1630 & medium & C-C stretching & 1625 & medium & 1628 & $1600 \sim 1628$ \\
\hline 2248 & strong & C-N stretching & 2262 & medium & 2261 & 2230,2261 \\
\hline$\sim 3100$ & medium, broad & C-H stretching & 3082 & weak & $3056 \sim 3090$ & $3065 \sim 3099$ \\
\hline $3300 \sim 3500$ & medium, broad, & H-bonded O-H stretching & 3529 & medium & 3407 & $3385,3407,3484$ \\
\hline $3500 \sim 3580$ & strong & Unrestricted O-H stretching & 3582 & strong & 3578 & $\sim 3589$ \\
\hline
\end{tabular}

${ }^{\mathrm{a}}$ Calculated infrared intensity from mPW1PW91/6-31G(d,p) method by the broadened IR spectra assuming a Lorentzian line width of $10 \mathrm{~cm}^{-1}$.

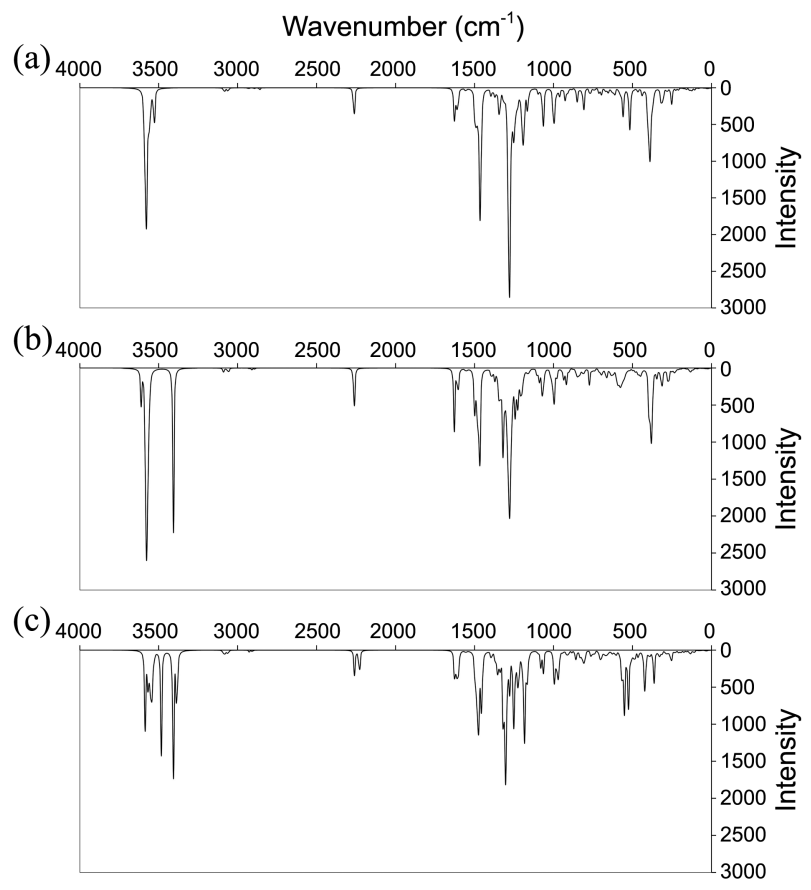

Figure 2. $m \mathrm{PW} 1 \mathrm{PW} 91 / 6-31 \mathrm{G}(\mathrm{d})$ calculated IR spectra $\left(\right.$ in $\left.\mathrm{cm}^{-1}\right)$ of the more stable conformers (a) $\mathbf{1}(r c t t)_{\mathrm{CHAIR}}$, (b) $\mathbf{1}(r t c t)_{\mathrm{CHAIR}}$, and (c) $\mathbf{1}(r c c t)_{1,2-\mathrm{A}}$ of $\mathbf{1}$.

ing on the presence of hydrogen bonds. Table 3 lists the common features of the three calculated conformational stereoisomers and an experimental IR spectrum. The first peak $\left(390-517 \mathrm{~cm}^{-1}\right)$ is due to the $\mathrm{O}-\mathrm{H}$ wagging motion. The second peak $\left(560-610 \mathrm{~cm}^{-1}\right)$ is attributed to the $\mathrm{C}-\mathrm{H}$ wagging motion and the out-of-plane bending vibrations of the four cyanophenyl rings. The third peak $\left(773-875 \mathrm{~cm}^{-1}\right)$ is attributed to the concerted motion of the $\mathrm{C}-\mathrm{O}$ stretching and $\mathrm{O}-\mathrm{H}$ wagging vibrations. The next three peaks (974-1520 $\mathrm{cm}^{-1}$ ) are due to the numerous concerted vibrations of $\mathrm{C}_{\mathrm{ar}} \mathrm{O}$ bond stretching, $\mathrm{C}-\mathrm{C}_{\mathrm{ar}}$ bond stretching, and $\mathrm{CCC}_{\mathrm{ar}}$ angle bending. The peaks at $2230-2262 \mathrm{~cm}^{-1}$ are assigned to $\mathrm{CN}$ triple stretching vibrations. $\mathbf{1}(\text { rcct })_{12 \mathrm{~A}}$ shows two $\mathrm{CN}$ bond stretching vibrations (2230 and $2261 \mathrm{~cm}^{-1}$ ), as opposed to the single $\mathrm{CN}$ stretching peak of the $\mathbf{1}(r c t t)_{\text {CHAIR }}$ or $\mathbf{1}(r t c t)_{\text {CHAIR }}$ isomer, the intensity of which is weaker than that of the experimental peak of $\mathbf{1}(r c t t)_{\text {CHAIR. The peaks }(3050-3100}$ $\mathrm{cm}^{-1}$ ) are composed of low-intensity lines corresponding to $\mathrm{C}-\mathrm{H}$ stretching vibrations.

From the last two rows of Table 3, it is seen that the peaks (3300-3500 $\mathrm{cm}^{-1}$ ) due to the restricted $\mathrm{O}-\mathrm{H}$ bond stretchings are shifted to the lower-frequency range as compared to the free $\mathrm{O}-\mathrm{H}$ vibrational frequencies $\left(3500-3600 \mathrm{~cm}^{-1}\right)$. The extent of shift depends on the relative strength of the hydrogen bond between the hydroxyl hydrogen atom and the hydroxyl oxygen and/or the nitrogen atom of the cyanophenyl group. As listed in Table 3, $\mathbf{1}(\text { rcct })_{12 \mathrm{~A}}$ shows three extra H-bonded O-H bond stretching vibrations $(3385,3407$, and $\left.3484 \mathrm{~cm}^{-1}\right)$ as compared to $1(r c t t)_{\text {CHAIR }}$, which proves that hydrogen bonding plays the primary role in the stability of the conformational stereoisomers of $\mathbf{1}$.

\section{Conclusion}

The total electronic and Gibbs free energies and normal vibrational frequencies of the different structures from four major conformations (CHAIR, TABLE, and 1,2-A) of the four stereoisomers [1 $(r c c c), \mathbf{1}(r c c t), \mathbf{1}(r c t t)$, and $\mathbf{1}(r t c t)]$ were optimized using mPW1PW91 (hybrid HF-DF) calculation methods. $\mathbf{1}(r c c t)_{1,2-\mathrm{A}}, \mathbf{1}(r c t t)_{\mathrm{CHAIR}}$, and $\mathbf{1}(r t c t)_{\mathrm{CHAIR}}$ were the more stable conformations of the respective stereoisomers. The calculated results correlated well with the experimental structures obtained from X-ray crystallography. Hydrogen bonding is the primary factor for the relative stabilities of the 
various conformational stereoisomers, and maximizing the $\pi-\pi$ interaction between the cyanophenyl rings is the secondary factor. The calculated IR spectra of the more stable conformers [1 $(r c t t)_{\mathrm{CHAIR}}, \mathbf{1}(r c c t)_{1,2-\mathrm{A}}$, and $\left.\mathbf{1}(r t c t)_{\mathrm{CHAIR}}\right]$ were compared with the experimental IR spectrum of $\mathbf{1}(r c t t)_{\text {CHAIR }}$.

Supplementary Material. All calculated structures of three conformers (CHAIR, TABLE, and 1,2-Alternate) of the respective stereoisomers [1 $(r c c c), \mathbf{1}(r c c t), \mathbf{1}(r c t)$, and $\mathbf{1}(r t c t)]$ are reported.

Acknowledgments. This work was supported by the IT R\&D program of MoTIE/MISP/KEIT (10044580, Korea).

\section{References}

1. Calixarenes, a Versatile Class of Macrocyclic Compounds, Topics in Inclusion Science; Vicens, J., Böhmer, V., Eds.; Springer Verlag: Berlin, 1990; p 280.

2. Gutsche, C. D. Calixarenes Revisited; Royal Society of Chemistry: Cambridge, 1998; vol. 6.

3. Calixarenes in Action; Mandolini, L., Ungaro, R., Eds.; World Scientific Publishing Company: Hackensack, NJ, 2000; 271.

4. Gutsche, C. D. Calixarenes: An Introduction (Monographs in Supramolecular Chemistry); Royal Society of Chemistry: Cambridge, UK, 2008; p 248.

5. Modern Supramolecular Chemistry: Strategies for Macrocycle Synthesis; Diederich, F. P., Stang, P. J., Tykwinski, R. R., Eds.; Wiley-VCH Verlag GmbH \& Co.: Weinheim, 2008; 400.

6. Sliwa, W.; Kozlowski, C. Calixarenes and Resorcinarenes: Synthesis, Properties, and Applications; Wiley-VCH Verlag GmbH \& Co.: Weinheim, 2009.

7. Dalgarno, S. J.; Power, N. P.; Atwood, J. L. Coord. Chem. Rev. 2008, 252, 825

8. Baldini, L.; Bracchini, C.; Cacciapaglia, R.; Casnati, A.; Mandolini, L.; Ungaro, R. Chem. Eur. J. 2000, 6, 1322.

9. Jain, V. K.; Pillai, S. G.; Pandya, R. A.; Agrawal, Y. K.; Shrivastav, P. S. Anal. Sci. 2005, 21, 129.

10. Cram, D. J. Science 1983, 219, 1177.

11. Cram, D. J.; Cram, J. M. Container Molecules and Their Guests; Royal Society of Chemistry: Cambridge, 1994.

12. Green, J. O.; Baird, J. H.; Gibb, B. C. Org. Lett. 2000, 2, 3845.

13. Gutsche, C. D. Calixarenes; Royal Society of Chemistry: Cambridge, 2008.

14. Gerkensmeier, T.; Iwanek, W.; Agena, C.; Fröhlich, R.; Kotila, S.; Näther, C.; Mattay, J. Eur. J. Org. Chem. 1999, 2257.

15. Dalgarno, S. J.; Tucker, S. A.; Bassil, D. B.; Atwood, J. L. Science 2005, 309, 2037.

16. Antesberger, J.; Cave, G. W.; Ferrarelli, M. C.; Heaven, M. W.; Raston, C. L.; Atwood, J. L. Chem. Commun. 2005, 892.

17. (a) Tiefenbacher, K.; Rebek, J. J. Am. Chem. Soc. 2012, 134, 2914. (b) Kleinhans, D. J.; Arnott, G. E. Dalton Trans. 2010, 39, 5780.

18. Kuzmicz, R.; Kowalska, V.; Domagala, S.; Stachowicz, M.; Wozniak, K.; Kolodziejski, W. J. Phys. Chem. 2010, 114B, 10311.

19. Benosmane, N.; Guedioura, B.; Hamdi, S. M.; Hamdi, M.; Boutemeur, B. Materials Science and Engineering C 2010, 30, 860.

20. Durola, F.; Rebek, J., Jr. Angew. Chem. Int. Ed. 2010, 49, 3189.

21. Pochorovski, I.; Breiten, B.; Schweizer, W. B.; Diederich, F. Chem. Eur. J. 2010, 16, 12590.

22. Nishimura, N.; Kobayashi, K. J. Org. Chem. 2010, 75, 6079.

23. Jin, P.; Dalgarno, S. J.; Atwood, J. L. Coord. Chem. Rev. 2010, 254,1760

24. Negin, S.; Daschbach, M. M.; Kulikov, O. V.; Rath, N.; Gokel, G.
W. J. Am. Chem. Soc. 2011, 133, 3234.

25. Fowler, D. A.; Tian, J.; Barnes, C.; Teat, S. J.; Atwood, J. L. Cryst. Eng. Comm. 2011, 13, 1446.

26. Kline, K. K.; Fowler, D. A.; Tucker, S. A.; Atwood, J. L. Chem Eur. J. 2011, 17, 10848 .

27. Mossine, A. V.; Kumari, H.; Fowler, D. A.; Maerz, A. K.; Kline, S. R.; Barnes, C. L.; Atwood, J. L. Isr. J. Chem. 2011, 51, 840.

28. Whetstine, J. L.; Kline, K. K.; Fowler, D. A.; Ragan, C. M.; Barnes, C. L.; Atwood, J. L.; Tucker, S. A. New J. Chem. 2010, 34, 2587.

29. Shivanyuk, A.; Friese, J. C.; Doring, S.; Rebek, J., Jr. J. Org. Chem. 2003, 68, 6489.

30. Shivanyuk, A.; Rebek, J., Jr. Chem. Commun. 2001, 2374.

31. Shivanyuk, A.; Rissanen, K.; Kolehmainen, E. Chem. Commun. 2001, 1107.

32. Murayama, K.; Aoki, K. Chem. Commun. 1998, 607.

33. Rose, K. N.; Barbour, L. J.; Orr, G. W.; Atwood, J. L. Chem. Commun. 1998, 407.

34. Atwood, J. L.; Barbour, L. J.; Jerga, A. Chem. Commun. 2001, 2376.

35. Atwood, J. L.; Barbour, L. J.; Jerga, A. J. Supramol. Chem. 2001, 1,131 .

36. Gerkensmeier, T.; Iwanek, W.; Agena, C.; Frohlich, R.; Kotila, S.; Nather, C.; Mattay, J. Eur. J. Org. Chem. 1999, 2257.

37. Fowler, D. A.; Atwood, J. L.; Baker, Chem. Commun. 2013, 49, 1802.

38. Dalgarno, S. J.; Power, N. P.; Warren, J. E.; Atwood, J. L. Chem. Commun. 2008, 1539.

39. Power, N. P.; Dalgarno, S. J.; Atwood, J. L. New J. Chem. 2007, $31,17$.

40. Dalgarno, S. J.; Cave, G. W. V.; Atwood, J. L. Angew. Chem., Int. Ed. 2006, 45, 570 .

41. Kulikov, O. V.; Daschbach, M. M.; Yamnitz, C. R.; Rath, N.; Gokel, G. W. Chem. Commun. 2009, 7497.

42. Jeon, Y. J.; Kim, H.; Kim, K.; Lee, M.; Han, C.; Kim, K.-J. Bull. Korean Chem. Soc. 2008, 29, 2284.

43. HyperChem Release 8, Hypercube, Inc.: Waterloo, Ontario, Canada, 2009.

44. Choe, J.-I.; Kim, K.; Chang, S.-K. Bull. Korean Chem. Soc. 2000, $21,465$.

45. Zhao, Y.; Tishchenko, O.; Truhlar, D. G. J. Phys. Chem. B 2005, 109, 19046.

46. Adamo, C.; Barone, V. J. Chem. Phys. 1998, 108, 664.

47. Lynch, B. J.; Fast, P. L.; Harris, M.; Truhlar, D. G. J. Phys. Chem. A 2000, 104, 4811 .

48. Frisch, M. J.; Trucks, G. W.; Schlegel, H. B.; Scuseria, G. E.; Robb, M. A.; Cheeseman, J. R.; Montgomery, J. A., Jr.; Vreven, T.; Kudin, K. N.; Burant, J. C.; Millam, J. M.; Iyengar, S. S.; Tomasi, J.; Barone, V.; Mennucci, B.; Cossi, M.; Scalmani, G.; Rega, N.; Petersson, G. A.; Nakatsuji, H.; Hada, M.; Ehara, M.; Toyota, K.; Fukuda, R.; Hasegawa, J.; Ishida, M.; Nakajima, T; Honda, Y.; Kitao, O.; Nakai, H.; Klene, M.; Li, X.; Knox, J. E.; Hratchian, H. P.; Cross, J. B.; Bakken, V.; Adamo, C.; Jaramillo, J.; Gomperts, R.; Stratmann, R. E.; Yazyev, O.; Austin, A. J.; Cammi, R.; Pomelli, C.; Ochterski, J. W.; Ayala, P. Y.; Morokuma, K.; Voth, G. A.; Salvador, P.; Dannenberg, J. J.; Zakrzewski, V. G.; Dapprich, S.; Daniels, A. D.; Strain, M. C.; Farkas, O.; Malick, D. K.; Rabuck, A. D.; Raghavachari, K.; Foresman, J. B.; Ortiz, J. V.; Cui, Q.; Baboul, A. G.; Clifford, S.; Cioslowski, J.; Stefanov, B. B.; Liu, G.; Liashenko, A.; Piskorz, P.; Komaromi, I.; Martin, R. L.; Fox, D. J.; Keith, T.; Al-Laham, M. A.; Peng, C. Y.; Nanayakkara, A.; Challacombe, M.; Gill, P. M. W.; Johnson, B.; Chen, W.; Wong, M. W.; Gonzalez, C.; Pople, J. A. Gaussian 09, Revision C.01, Gaussian, Inc., Wallingford CT, 2009.

49. Foresman, J. B.; Frisch, A. Exploring Chemistry with Electronic Structure Methods (Second Edition); Gaussian, Inc. Pittsburgh, PA, 1996; p 63.

50. Lee, S. J.; Chung, H. Y.; Kim, K. S. Bull. Korean Chem. Soc. 
2004, $25,1061$.

51. GaussView, Version 5, Dennington, Roy; Keith, Todd; Millam, John. Semichem Inc., Shawnee Mission, KS, 2009.

52. Han, J.; Song, X.; Liu, L.; Yan, C. J. Incl. Phenom. Macrocycl. Chem. 2007, 59, 257.
53. Yan, C.; Chen, W.; Chen, J.; Jiang, T.; Yao, Y. Tetrahedron 2007, 63, 9614.

54. Castineiras, A.; Sicilia-Zafra, A. G.; Gonzalez-Perez, J. M.; Choquesillo-Lazarte, D.; Niclos-Gutierrez, J. Inorg. Chem. 2002, 41,6956 . 